\title{
Awareness of and Preparedness for Digital Broadcasting among Communication Practitioners and Educators in Uyo
}

\author{
By Charles Obot $t^{\dagger}$ \\ Idaresit Idongesit Inwang*
}

The digitization of broadcasting is considered one of the most significant developments in the broadcasting industry. Communication practitioners and educators are expected to play key roles in the digitization process. The objectives of the study were; to investigate the level of awareness of the oncoming digitization project among communication educators, to ascertain the level of preparedness of the communication practitioners for the transition to digital broadcasting, to find out the possible implications of full digitization on communication education in Nigeria, to investigate the implications of digital broadcasting on programming and content production, and to find out possible challenges communication educators and practitioners in Uyo would face during digital broadcasting. The population of this study comprised all the communication practitioners in television stations in Uyo, Nigeria who work in the news, programming and engineering departments. Communication educators who teach communication courses in tertiary institutions in Uyo also constituted the population of the study. Communication educators in tertiary institutions and communication practitioners in broadcast stations, especially those in the news, programming and engineering departments in Uyo, Nigeria were considered the most appropriate subjects for the study. The survey method was adopted for this study. The research instrument (questionnaire) was administered directly to the respondents by the researchers. Based on the findings of the study, it is concluded that communication educators in Uyo are aware of the digitization process in the broadcast industry and are already teaching the subject of digitization in tertiary institutions in Uyo, Nigeria in courses including Trends in Media Technology, Information and Communication Technology, among others.

Keywords: analog broadcasting, communication educators, communication practitioners, digital broadcasting, preparedness

\section{Introduction}

From inception, television broadcasting in Nigeria has been accomplished by analog transmission which uses complete waves to transmit pictures and sound. Over the years, the transmission process has improved incrementally. It moved from monochrome (black and white) to color transmission, and recently it has begun the transition into the digital format. Digital broadcasting is superior to the analog format because of some advantages such as improved signal quality, versatility, efficiency and interoperability with other electronic media. "Digital signals have as an additional advantage, the capability of generating no noise and are more resistant to signal interference" (Idoko, 2010, p. 5). This new technology allows audio, video and data to be transmitted over airwaves like a computer.

\footnotetext{
${ }^{\dagger}$ Senior Lecturer, Department of Communication Arts, University of Uyo, Nigeria.

* Alumna, Department of Communication Arts, University of Uyo, Nigeria.
} 
Due to the dynamic nature of technology and the fact that the analog system currently in use may be unable to support future developments in the industry, there is a dire need to make this change so that the country can keep up with other nations and meet the demands of the age.

The International telecommunications Union set aside the year 2015 as a deadline for the transfer from analog to digital broadcasting. This trend has remained a challenge to both public and private broadcasting outfits, especially in Africa, a continent that includes Nigeria. It is unarguable to state that to be in a leading position in today's highly technological and competitive world of broadcasting, Nigeria must strive to acquire and utilize the state-of-the-art information and communication technology in its daily news, program transmissions and perhaps entire broadcasting operations. Anything short of this will spell doom for the country's broadcasting operations.

Digital broadcasting has exceptional benefits which cover information gathering, processing, storage, retrieval and transmission among others that will indeed revolutionize the entire broadcasting industry. As practitioners in the state prepare to join the entire country and the world at large to transmit digitally, there is a critical and urgent need for them to be prepared and anticipate the changes involved. This makes publicity and training necessary. Communication educators are expected to teach and train students on skills necessary in the practice of communication, including broadcasting. Thus, with the advent of the new technology in broadcasting, students ought to be taught the implications and imperatives of digitization. How far have they gone with this? People need to be adequately informed of the benefits, implications, and processes involved (before and after the change).

The communication practitioners need to know about and also get properly prepared for the change, in order to match manpower with the new system. How far have they come with this? These concerns arise against the backdrop of the fact that digital broadcasting will affect various segments of the broadcasting chain such as production, transmission and reception, presentation etc.

In sum, to what extent are they mobilized for the project? Thus, to what extent are the communication practitioners and educators aware of and prepared for digital broadcasting in Uyo?

\section{The Concept of Digitization}

Digitization is defined as a process through which information, whether relayed through sound, text, voice or image is converted into a digital binary language for computer use (Okorie, 2008). This makes possible the conversion of information from different sources through one channel, and reduces the risk of distortion.

"Through digitization, the capacity of communication channels are greatly expanded, there is more scope for consumer choice and more possibilities for interactive system" (Kombol, 2008, p. 6). Furthermore, digitization considerably improves the quality of voice and video transmission and economic efficiency is 
enhanced because conversion to digital forms of storage, editing and retrieval also saves time and labor. For high quality video, for example, images can be digitally compressed and then transmitted over satellites at 56,000 bits per second as a computer file. This digital data can be stored on a disc system until it is played back at the original speed. Since digital compression and storage systems are lightweight, the new technology can be especially useful in newsgathering. Digitization of video signals reduces their size; therefore, more information can be carried over phone wires and stored (Baran, 2010).

Digital broadcasting is different from analog in many ways. One major difference is the transmission of signals. In the United Kingdom, Kombol (2008) states that the signal for digital transmission is transmitted in four different ways: cable, satellite, digital terrestrial television and telephone connection.

- Cable: Cable has the capacity of transmitting about 200 digital television channels for viewers at home. Furthermore, cable services can also provide fast internet access and a standard telephone connection. This versatile nature ensures the use of the returning path by viewers.

- Satellite: In most cases, satellite provides one digital transmission service and has a capacity for hundreds of channels. It is feasible for satellites to provide a two-way path, but more often than not, only a one-way service is provided

- Digital Terrestrial Television: This television broadcast is a land-based transmitter network. Signals broadcast through this means are received by antenna-enabled television. In this service, there is no return path. Thus, it is a one-way affair.

- Telephone Connection: In most advanced countries of the world, the bandwidth of telephone service is increased to also convey television signals. With this technology, the viewer chooses one television program and it is transmitted to their home.

Obviously, digital broadcasting has many advantages over analog. Program presentation would be well improved by the time analog transmission is all over. This is true in terms of clarity and quality of signals and spectrum efficiency. The technology has opened a world of possibilities for broadcasting. A huge spectrum will be available for television broadcasts in the country, argues Ocholi (2009, p. 2). As a result, more frequencies will be available for television stations in the country. It will afford the industry opportunities for interactive broadcasting as television sets will be able to do much more than receive signals.

\section{Analog vs. Digital Television}

The analog mode of television broadcasting is gradually paving the way for the new digital transmission technology in television broadcasting. Both methods have certain properties that distinguish one from another. Thus, Leke (2000) particularly focuses on the differences between analog and digital 
television, apart from other issues regarding the digital migration in the broadcast industry.

He noted that the analog mode of television transmission has contributed its own quota to the broadcast industry despite its few lapses, but the digital technology has emerged as a solution to the problems inherent in the analog system. According to him, adjacent analog transmission were found to be subject to interference, forcing the regulatory bodies to leave space between channels and only allocate a small percentage of the available spectrums to ensure high quality transmission and reception throughout the regions served.

Some of the major differences between digital and analog broadcasting, as cited in Kombol, (2008) are as follows:

- Analog broadcasting uses 6MHL of spectrum. This wastes bandwidth and is grossly inefficient in sound and picture quality. Digital broadcasting transmits pictures and sound of significantly higher quality with the same 6MHL spectrum, yet it also frees up the space that can be used for other essential services such as emergency broadcasts etc. Digital television occupies less bandwidth per program.

- Analog broadcasting compresses and creates space and can allow up to six channels to be aired the same time.

- Analog broadcasting provides no Internet access, just programs. Digital broadcasting not only provides access to television programs, but Internet access to many fields of endeavor across the world.

- Digital broadcasting allows for interactive television, where apart from Internet services, viewers can also give feedback through their TV sets. This was not possible with the analog TV.

- In digital broadcasting, multiple signals are transmitted in one of four ways: cable, satellite, digital terrestrial TV or telephone communication.

- Digital signals react differently to interference than analog signals.

Indeed, the digital technology has opened a world of possibilities in broadcasting as opposed to the previous analog system.

\section{Digital Television, Content Production and Signal Transmission}

In the Communique issued at the extraordinary meeting on digitization of broadcasting and national security of the National Council of Information (NCI) in July, 2014, participants emphasized that in the digital era, content is king. All broadcasts would need to do is move their programs from their analog transmitter to the signal distributor. Ofose (2013) supported this position but expressed fear that happenings in the industry have not portrayed the government as being ready to embrace the digital culture. He opined that Nigerians need to be provided with quality contents or multiple channels at an affordable cost or for free. Content that is relevant to the Nigerian audience should be deliberately created. Our values should be protected by the NBC by 
ensuring that producers are able to produce local programs instead of relying heavily on cheap foreign programs.

Also, social media should be explored in marketing producers' content. The great potential of digital production equipment and multiple sales points which the digital era has opened up for marketing programs also needs to be explored. Furthermore, producers should make an effort to explore content focusing on everyday life and people, showcasing the uniqueness that makes us human.

However, he expressed concern over the fact that platform providers were becoming more selective and demanding for content channel exclusivity. This could hinder content/channel distribution or viewing by the public. He quoted a content developer who pleaded anonymity but said that the success of a channel or content should not be based on the amount of money spent in developing or acquiring it, but the number in the audience who are able to have access to such a channel/content and the positive impact it has on their lives.

However, he argued that television viewing is not a social class issue, and should not be treated as such. He concluded that the more quality information or content made easily available to Nigerians, the better our society and the country.

\section{Digitization and Challenges of Broadcasting in Nigeria}

Analog broadcasting has been in existence in the country for a long time and has contributed to the development of the broadcast industry over the years. The advent of digital technology will revolutionize broadcasting and solve many of the problems that were inherent in the analog system.

Innocent (2012) acknowledges the fact that digitalization is indeed the current trend in broadcasting, both in Nigeria and the world over - an innovation that will change the scope of broadcasting in the country and beyond. He highlighted the many advantages of digital broadcasting which include; clear and quality signals, multiple channels and more programming choices for viewers.

But in spite of these benefits, he noted some factors that could pose a challenge to the process and it could take time to work on some of the chief challenges which formed the crux of his discussion. They include:

- Technical and Financial Challenges: The switchover from analog to digital broadcasting requires huge investments in equipment and gadgets. This of course requires money. This issue was viewed in two parts: The involvement of the broadcasters and the implications for the audience. Broadcasters need new transmission and production equipment. In this vein, broadcasting organizations like NTA or FRCN will be hit severely. Also, the masses will be seriously affected. Many Nigerians are of low economic level, and this would mean a Herculean task for all the audience who would have to either buy a digital television set or a set top box after the digital switch over. 
- Power Supply: The country has an unstable power sector and that is not encouraging. The country has spent huge sums of money to revive the power supply, but to no avail. Thus, in the opinion of Innocent (2012), the epileptic power supply in the country and the inevitable dependence on generators poses a big challenge for the digitization process.

- Manpower: As complex and fragile equipment is coming in, there is need for matching manpower with equipment and processes. Training and retraining of personnel to fit into the digitization process will be a challenge. Joseph (2013) had observed in line with this, that the digitization of the broadcast industry will bring a lot of changes, and a good number of existing broadcast personnel may not be able to adjust to the new system. He added that some of the existing personnel may be adversely affected too. Those who will not be able to understand the flexibility and or cope with the fragility of the new technology may be thrown out. This will result in the burden of unemployment.

However, Innocent (2012) concluded by suggesting that there should be a massive sensitization by government, policy makers, stakeholders and officials, as this will contribute positively to the process and reduce incomprehensibility. Furthermore, there should be a convergence of broadcasting with other related technologies - for instance between MTN and DSTV. This, he opined will extend the potential of digital signal transmission. In addition, the government should promulgate laws that will enhance delivery and affordability. This is necessary, even as they find a lasting solution to the power problem.

- Theoretical Framework: The theoretical framework of this study is the Diffusion of Innovation and the Technological Determinism Theories.

\section{Diffusion of Innovation Theory}

According to Baran and Davis (2009, p. 271), diffusion of innovation theory is credited to Everett Rogers. The theory is an extension of Paul Lazarsfeld's original idea of two-step flow of information. It traces the process by which a new idea or practice is communicated through certain channels, among members of a social system.

"Diffusion is a special type of communication concerned with the spread of messages that are perceived as new ideas. An innovation is an idea, product, object or practice that is perceived as new by an individual" (Asemah, 2011, p. 162).

This theory emphasizes the communication of an idea or discovery to members of a social system. Through mass and inter-personal communication channels, people can get information, and also perceive its usefulness.

According to Asemah, whenever there is a new product, idea or service to be announced to the public, the mass media is the best means. This is attributed to the fact that the media have been held to be very important in spreading new ideas or passing on new innovations to people. 


\section{Technological Determinism}

The theory states that technology, especially the media, decisively shape how individuals think, feel and act, and how societies organize themselves and operate, as we move from one technological age to another. This means that we learn, feel and think the way we do because of the messages we receive through the current technology or medium available. The medium is therefore the message. As the medium changes, so does the society's way of communicating.

Through his theory McLuhan (1964) explains that when new systems of technology are developed, the culture of the society is immediately changed to reflect the changes needed to use the new technology. There is a simple cause and effect analysis here between the introduction of new technology and the changes in society's way of thinking feeling, acting or believing.

In his theory McLuhan also added that there have been different periods of time, and each period had different characteristics with regards to communication. These periods include the tribal age, the literate age, the print age and the electronic age.

The tribal age was the age when man's perception of his environment was multi-sensory and his mode of communication was oral. The literate age brought people out of collective tribal involvement into civilized private detachment. Literacy gradually evolved and marked a step away from the tribal age as people could begin to use their eyes to read materials. The print age made the usual dependence of the literate age widespread. This is because the print age resulted in the mass production of several written products. He added that this age is the ICT era where communication now transcends both national and planetary boundaries. Information gathering, dissemination and interaction has changed. This is true even for the broadcast media with the advent of digital broadcasting that will practically replace the analog mode of transmission.

\section{Objectives of the Study}

The objectives of this study are to:

- investigate the level of awareness of the oncoming digitization project among communication educators in Uyo,

- ascertain the level of awareness and preparedness of the communication practitioners for the transition to digital broadcasting,

- find out the possible implications of full digitization on communication education in Nigeria,

- investigate the possible implications of digital broadcasting on programming and content production, and

- find out possible challenges of digital broadcasting transition among communication practitioners in Uyo. 


\section{Research Questions}

The study focused on the following research questions:

- What is the level of awareness of the oncoming digitization project among communication educators?

- What is the level of preparedness of the communication practitioners for the transition to digital broadcasting?

- What are the possible implications of full digitization on communication education in Nigeria?

- What are the possible implications of digital broadcasting on programming and content production?

- What possible challenges will the digital broadcasting transition pose for communication practitioners in Uyo?

\section{Scope of the Study}

The study specifically focuses on the precise level of awareness and preparedness for digital broadcasting among communication practitioners and educators in Uyo.

\section{Justification of the Study}

This study is timely because it is one of the most current and prominent issues in the broadcasting industry the world over, especially as the final switch over date for the whole world is barely months away. Also, it will be of immense benefit to Nigerians, (especially media professionals) as it focuses on appropriate sensitization and preparation needed to make digital broadcasting a reality. Furthermore, students of mass communication and other related fields will find the work useful as it touches their area of specialization.

\section{Research Methodology}

To achieve the objectives of the study, the survey method of research was adopted, using the questionnaire as the research instrument.

Sampling size. Based on the administrative department of both stations, the entire population of the communication practitioners was 156 , while the total number of educators from both institutions was 37 , as also listed by the administrative departments of the institutions. The final list includes a total of 193 in the population.

Sampling procedure. A census of the entire population of communication practitioners and communication educators in Uyo was taken. Two tertiary institutions and two broadcasting stations in Uyo formed the population of the study respectively. 


\section{Results and Discussion}

\section{Research Question 1}

What is the level of awareness of the oncoming digitization project among communication educators in Uyo?

Table 1 reveals that $100 \%$ of the respondents know about the upcoming digital broadcast transition in Nigeria. It is therefore established that all the educators are aware of the upcoming digital transition in the broadcast industry.

In Table 2 it is further established that 24, representing $80 \%$ of the respondents, have personally been exposed to digital broadcasting transition messages.

Moreover, Table 3 establishes the sources of these messages and reveals that $3(13 \%)$ of the respondents heard these messages through radio, $12(50 \%)$ saw the messages on television, 7 (29\%) received the messages through newspaper, while $2(8 \%)$ read about them from scholarly articles.

Data from Table 4 also shows the frequency of the messages and it can be seen that $6(25 \%)$ of the respondents often do see or hear these messages, 10 $(42 \%)$ sometimes do, while $8(33 \%)$ rarely do.

Based on these responses, it is evident that the communication educators have been exposed to messages about digital broadcasting from various sources.

One of the core assumptions of the Diffusion of Innovation theory is that there are opinion leaders who have a role to play in the spread of information about an innovation. This is because they have more social experience and exposure than the "opinion followers." This in turn can influence the knowledge, opinion, judgment and subsequent adoption of the innovation by the followers.

Table 1. Respondents' Awareness of Oncoming Digital Broadcast Transition in Nigeria

\begin{tabular}{|l|c|c|}
\hline Response & No. of Respondents & Percentage \\
\hline Yes & 30 & 100 \\
\hline No & - & - \\
\hline Do not know & - & - \\
\hline Total & $\mathbf{3 0}$ & $\mathbf{1 0 0}$ \\
\hline
\end{tabular}

Table 2. Respondents' Exposure to Digital Broadcasting Transition Message

\begin{tabular}{|l|c|c|}
\hline Response & No. of Respondents & Percentage \\
\hline Yes & 24 & 80 \\
\hline No & 6 & 20 \\
\hline Total & $\mathbf{3 0}$ & $\mathbf{1 0 0}$ \\
\hline
\end{tabular}

Table 2 shows that most of the respondents (24) were exposed to the Digital Broadcasting Transition message. 
Table 3. Sources of Digital Transition Messages

\begin{tabular}{|l|c|c|}
\hline Sources & No. of Respondents & Percentage \\
\hline Radio & 3 & 13 \\
\hline Television & 12 & 50 \\
\hline Newspaper & 7 & 29 \\
\hline Scholarly articles & 2 & 8 \\
\hline Total & $\mathbf{2 4}$ & $\mathbf{1 0 0}$ \\
\hline
\end{tabular}

Table 3 shows that television was the major source of message on digital broadcasting transition.

Table 4. Frequency of Digital Transition Messages Seen or Heard

\begin{tabular}{|l|c|c|}
\hline Response & No. of Respondents & Percentage \\
\hline Often & 6 & 25 \\
\hline Sometimes & 10 & 42 \\
\hline Rarely & 8 & 33 \\
\hline Total & $\mathbf{2 4}$ & $\mathbf{1 0 0}$ \\
\hline
\end{tabular}

Table 4 shows that most respondents (10) were exposed to digital broadcasting messages "sometimes."

\section{Research Question 2}

What is the level of awareness and preparedness of the communication practitioners for the transition to digital broadcasting.

Table 5 reveals that 75 respondents, representing $54 \%$ of the population, were very familiar with the proposed transition of digital broadcast stations in Nigeria. Ten respondents, representing $7 \%$ of the population, were not familiar at all. Fifty-four 54 (37\%) were somewhat familiar and 7 (5\%) were undecided.

This result is in contrast to one of the findings of a study by Mark (2010). Mark mentioned that there was low awareness of the digitization process among the broadcasters in Nigeria, apart from the populace. Results from the current study show that at least $51 \%$ of the population was very familiar with the upcoming transition and $37 \%$ were somewhat familiar with it.

With regards to preparedness, Table 6 reveals that 63 respondents agreed that several measures have been taken to equip practitioners with the necessary skills and knowledge for the upcoming transition, 40 respondents strongly agreed with this, 14 respondents disagreed and 23 others strongly disagreed with the assertion. Table 7 further reveals that some of these measures included seminars, training sessions, workshops and discussions during departmental meetings. However, in Table 8, 48 respondents said these measures were rarely organized, 41 respondents said they were sometimes organized while 36 others said they were often organized. Table 9 further reveals that $56 \%$ of the respondents have personally attended these measures for training while $44 \%$ have not.

This result is supported by the findings of Williams (2010), who said that adequate training of staff was one of the challenges faced by stations in their preparation for digital transition, even though staff members had a positive 
attitude towards the adoption of the technology in the broadcast industry. He explained that this robs them of adequate knowledge of what a full digitization process entails.

Based on the findings of this current study, training measures have not been consistent enough to adequately inform and equip the practitioners with the necessary skills and knowledge for the upcoming transition.

In the Technological Determinism theory, McLuhan explains that when new systems of technology are developed the culture of the society is immediately changed to reflect the changes needed to use the new technology. Consequently, digital broadcasting will change how broadcast practitioners will organize themselves and operate based on what the new technology demands, as they move from the analog technology to digital transmission. This calls for proper training.

Table 5. Respondents' Level of Familiarity with Oncoming Digitization of Broadcast in Nigeria

\begin{tabular}{|l|c|c|}
\hline Response & No. of Respondents & Percentage \\
\hline Very familiar & 75 & 51 \\
\hline Not familiar at all & 10 & 7 \\
\hline Somewhat familiar & 54 & 37 \\
\hline Do not know & 7 & 5 \\
\hline Total & $\mathbf{1 4 6}$ & $\mathbf{1 0 0}$ \\
\hline
\end{tabular}

Table 5 shows that a majority of the respondents (75) were very familiar with the digitization project in Nigeria.

Table 6. Acquaintance of Broadcast Practitioners with Necessary Knowledge and Skills for the Proposed Transition

\begin{tabular}{|l|c|c|}
\hline Response & No. of Respondents & Percentage \\
\hline Strongly agree & 40 & 27 \\
\hline Agree & 63 & 43 \\
\hline Strongly disagree & 23 & 16 \\
\hline Disagree & 14 & 10 \\
\hline Do not know & 6 & 4 \\
\hline Total & $\mathbf{1 4 6}$ & $\mathbf{1 0 0}$ \\
\hline
\end{tabular}

Table 6 shows that most of the broadcast practitioners (63) were acquainted with the knowledge and skills needed for digitization.

Table 7. Some Measures Used to Equip Practitioners

\begin{tabular}{|l|c|c|}
\hline Options & No. of Respondents & Percentage \\
\hline Seminars & 40 & 27 \\
\hline Training sessions & 29 & 20 \\
\hline Workshops & 55 & 38 \\
\hline Others & 4 & 3 \\
\hline None & 18 & 12 \\
\hline Total & $\mathbf{1 4 6}$ & $\mathbf{1 0 0}$ \\
\hline
\end{tabular}


Table 7 shows that workshops provided most of the platform used to equip practitioners with necessary skills and knowledge for digital programming.

Table 8. Frequency of the Measures

\begin{tabular}{|l|c|c|}
\hline Response & No. of Respondents & Percentage \\
\hline Often & 36 & 28 \\
\hline Sometimes & 41 & 32 \\
\hline Rarely & 48 & 38 \\
\hline Do not know & 3 & 2 \\
\hline Total & $\mathbf{1 2 8}$ & $\mathbf{1 0 0}$ \\
\hline
\end{tabular}

Data from Table 8 shows that the measures for training practitioners with the necessary skills, knowledge and equipment rarely took place.

Table 9. Personal Participation in the Measures

\begin{tabular}{|l|c|c|}
\hline Response & No. of Respondents & Percentage \\
\hline Yes & 72 & 56 \\
\hline No & 56 & 44 \\
\hline Total & $\mathbf{1 2 8}$ & $\mathbf{1 0 0}$ \\
\hline
\end{tabular}

Responses from Table 9 show that $56 \%$ of the respondents have personally attended sessions for training while $44 \%$ have not. Responses about why some of the practitioners did not personally attend any of these training measures varied. Some of the respondents noted that they were not employed before the period of training and they had no prior knowledge of such before their employment.

Others said most of them were yet to be nominated for such training programs especially those held outside their station of service. Some respondents also said that such programs had not yet been organized specifically for their department, while others stated they were absent during such sessions because of an official duty.

\section{Research Question 3}

What are the possible implications of full digitization on communication education in Nigeria?

Based on the data presented in Table 10, 2 respondents representing 7\% of the population agreed that students need to be taught about digital broadcasting, while 28 (93\%), strongly agreed. A majority of the educators in the state are of the opinion that the awareness campaign of the process has not been effective at all. This is seen in Table 11.

Concerning the question about how the full digital broadcasting process will affect communication education in Nigeria, some respondents said that the development will demand a review of the curriculum of communication departments and media studies in the country to develop courses on digital trends in broadcasting. Others said that the contents of the courses will also need to be reviewed to ensure that relevant issues are appropriately accommodated. The respondents said this is necessary and will enable students to learn the basics of the technology before their subsequent adoption in the near future. 
This position is supported by the Diffusion of Innovation theory, that emphasizes there should be communication about a new product, practice, object, or idea so people can be informed about it and also perceive its usefulness.

However, Table 12 reveals that there were already courses in the institution in Uyo that addressed the upcoming development. The courses mentioned include: Trends in Media Technology, Trends in Communication and Globalization, Computer-Assisted Reporting, Information and Communications Technology, New Media Studies and Broadcasting Management.

Table 10. Responses on Whether Students Should Be Taught about Digitization

\begin{tabular}{|l|c|c|}
\hline Response & No. of Respondents & Percentage \\
\hline Strongly agree & 28 & 93 \\
\hline Agree & 2 & 7 \\
\hline Strongly disagree & - & - \\
\hline Disagree & - & - \\
\hline Do not know & - & - \\
\hline Total & $\mathbf{3 0}$ & $\mathbf{1 0 0}$ \\
\hline
\end{tabular}

The data in Table 10 shows that all the respondents agreed that students should be taught about digitalization.

Table 11. Effectiveness of Awareness campaign about Oncoming Digital Broadcasting Transition

\begin{tabular}{|l|c|c|}
\hline Options & No. of Respondents & Percentage \\
\hline Very effective & 2 & 7 \\
\hline Somewhat effective & 10 & 33 \\
\hline Not effective at all & 16 & 53 \\
\hline Do not know & 2 & 7 \\
\hline Total & $\mathbf{3 0}$ & $\mathbf{1 0 0}$ \\
\hline
\end{tabular}

Table 11 shows that most of the respondents (16) considered the awareness campaign about the transition to digital broadcasting ineffective.

Table 12. Responses to the Question of whether There Are Courses that Have Addressed or Will Address the Upcoming Development

\begin{tabular}{|l|c|c|}
\hline Response & No. of Respondents & Percentage \\
\hline Yes & 24 & 80 \\
\hline No & 5 & 17 \\
\hline Cannot say & 1 & 3 \\
\hline Total & $\mathbf{3 0}$ & $\mathbf{1 0 0}$ \\
\hline
\end{tabular}

Table 12 shows that a majority of the respondents confirmed there were courses in their institutions' curricula that address digital broadcasting.

Those who agreed with this mentioned the courses included: Trends in Media Technology, Trends in Communication and Globalization, Internet and its Application, Computer-Assisted Reporting, Issues in Nigerian Mass Media 
History I and XII, Issues in Broadcasting, Information and Communication Technology, Broadcasting Management and New Media Studies.

\section{Research Question 4}

What are the implications for the impact of digital broadcasting on programming and content production?

Based on the data collected by the researcher, it is evident that digitization in the industry will bring certain changes that will affect transmission, reception, content production and programming.

Respondents asserted that digital broadcasting will bring diversity and also an extended range of programs and channels. According to them, this will broaden the choice for consumers, as channels will multiply.

Other benefits include, interactive television, improved quality output, better and clearer reception for consumers, improved news programs, better program compilation and editing and better signal transmission.

Moreover, several respondents simply explained that they were yet to fully know what the entire digitization process requires or its implications, as they were not yet appropriately oriented on the subject.

This result supports the assertion by Graham (2014) that digital broadcasting will need talents that can deliver the features, dramas, documentaries, news programs and signal transmission in the best ways to suit the technology. He expressed worry that the issue will constitute a problem if they are not trained and properly informed for these roles.

Also, the technological determinism theory explains that information gathering, dissemination and interaction will change in line with the current technology or medium available. Based on the findings of the study, there will be operational changes in the broadcast media with the advent of digital technology that will replace the analog mode of broadcasting and transmission. This means that broadcasters will need to change their mode of operations in line with everything the digital technology entails, although they are yet to be properly/sufficiently informed or trained for that.

\section{Research Question 5}

What are the possible challenges that digital broadcasting transition poses for communication practitioners in Uyo?

The answer to research question 5 is found in Table 13. The researcher was able to deduce that broadcast practitioners are facing certain challenges in their bid to adopt the digital broadcasting technology.

In Table 13, 33\% of the respondents were of the opinion that there was not enough skilled manpower for the process and $25 \%$ said equipment needed to be procured and installed and users need to be trained. Other challenges include computer illiteracy, funding, poor power supply and lack of quality program content. 
These findings are validated in a study by Mark (2010). He listed some of the common challenges facing the broadcast industry in the transition process including funding, inadequate skilled labor, lack of equipment, management of multi channels and incompetence in program and content production.

Thus, in view of the changes to be experienced with the use of the new technology, and the need to work towards the deadline for the final switchover, practitioners in the broadcasting industry are faced with certain challenges that may impede the process.

Table 13. Possible Challenges the Proposed Digital Broadcasting Transition Pose to Practitioners

\begin{tabular}{|l|c|c|}
\hline Challenges & No. of Respondents & Percentage \\
\hline Unskilled manpower & 48 & 33 \\
\hline Lack of equipment & 36 & 25 \\
\hline Computer illiteracy & 22 & 15 \\
\hline Funding & 17 & 12 \\
\hline Poor power supply & 8 & 5 \\
\hline Lack of quality program content & 15 & 10 \\
\hline Total & $\mathbf{1 4 6}$ & $\mathbf{1 0 0}$ \\
\hline
\end{tabular}

Table 13 shows that "unskilled manpower" constitutes the greatest challenge posed by the digital broadcasting transition.

Responding to how digital broadcasting will improve broadcasting operations in the departments, the respondents mentioned some of the benefits including: improved sound and picture quality, interactive television, an extended range of sports, music, education, weather and special interest channels, improved news gathering and transmission, improved signal transmission and a wider signal coverage area.

However some mentioned they were not sure of how much their daily operations would be affected because they had not received any orientation or training with regards to digital broadcasting.

\section{Data from Broadcast Practitioners}

Table 14. Department of Respondents

\begin{tabular}{|l|c|c|}
\hline Department & No. of Respondents & Percentage \\
\hline News & 40 & 27 \\
\hline Programming & 74 & 51 \\
\hline Engineering & 32 & 22 \\
\hline Total & $\mathbf{1 4 6}$ & $\mathbf{1 0 0}$ \\
\hline
\end{tabular}

Table 14 shows that staff of Programming Department formed the majority (74). 
Table 15. Educational Qualification of Respondents

\begin{tabular}{|l|c|c|}
\hline Qualification & No. of Respondents & Percentage \\
\hline WAEC/NECO & 35 & 24 \\
\hline OND/HND & 29 & 20 \\
\hline BA/MA & 82 & 56 \\
\hline PhD and above & - & - \\
\hline Total & $\mathbf{1 4 6}$ & $\mathbf{1 0 0}$ \\
\hline
\end{tabular}

Table 15 shows that employees with BA/MA constituted the largest number.

Table 16. Responses on whether Students Have already Been Educated on Digital Broadcasting

\begin{tabular}{|l|c|c|}
\hline Response & No. of Respondents & Percentage \\
\hline Yes & 17 & 57 \\
\hline No & 3 & 10 \\
\hline Cannot Say & 10 & 33 \\
\hline Total & $\mathbf{3 0}$ & $\mathbf{1 0 0}$ \\
\hline
\end{tabular}

The data in Table 16 shows that most of the respondents (17) said that students in their institutions have already been educated on digital broadcasting.

The respondents who said that students have already been educated said that has happened through lectures in class; especially when students are taught courses on the subject, during interaction with lecturers and other informal discussions within and outside the classroom.

Responding to how the transition to digital broadcasting will affect communication education in Nigeria, some respondents said that the development in the broadcast industry will demand a review of the curriculum of communication departments in the country to develop courses in digital trends in broadcasting.

They also said that a review of existing content of the courses will also be necessary to ensure that relevant issues are appropriately accommodated.

Others said that students in Nigerian universities will be better informed when properly taught on the subject, and thus will be more prepared for the industry in terms of knowledge of and practical experience in broadcasting. This, to them is because communication education will create awareness of their use of the digital technology, including the Internet.

\section{Conclusion}

Based on the findings of the study, it is concluded that communication educators in Uyo are aware of the digitization project in the broadcast industry and are already teaching the subject of digitization in tertiary institutions in Uyo, through various courses like Trends in Media Technology, Information and Communication Technology, etc. 
Findings from the study further reveal that digital broadcasting will improve picture and sound quality, lead to a number of additional channels, make television viewing interactive, extend the signal coverage area, improve news gathering and offer an extended range of programs for viewers.

This research has further revealed that communication practitioners in Uyo are not fully ready for the digital broadcasting transition due to some challenges including lack of adequate orientation and training as well as the funds to purchase needed equipment.

\section{Recommendations}

The following recommendations are made based on the findings of this study:

- That there is a need to carry out timely information and communication activities for the communication practitioners and educators, and even to the general public to raise awareness and understanding of digital broadcasting. This means conducting a massive awareness campaign that will not leave them in doubt of what digital broadcasting or the transition entails. A website could be created to serve as a portal to provide immediate access to information about digital broadcasting. The basic information could include the benefits of digital broadcasting and the process or preparation for migration.

- There should be immediate enlightenment of lecturers in order to promote and support the need to expose students in the tertiary institutions to the basics of digital broadcasting. The curricula should also be updated in order to ensure that courses that treat the subject in detail or perhaps exclusively are included as part of mainstream learning, including practical skills that will make the students learn how to use the technology.

- It is important that communication practitioners in the broadcasting industry be given adequate and consistent orientation and training in order to equip them with the necessary skills and knowledge for a successful and sustained use of the digital broadcasting technology. This is necessary for them to remain relevant in the new information communication era.

- Content producers need to be trained on content generation, processing, storage and transmission. This will enlighten them about how to focus on the quality of the content and programs. Broadcast engineers will need to be well versed in digital television transmission principles, as the modern technology will create a greater demand on their expertise. This too calls for training.

- That digital broadcasting equipment such as electronic news gathering equipment (ENG), news and programs processing equipment, teleprompter cameras, recording equipment and other devices will be needed to replace analog communication equipment.

- The switchover process calls for a huge capital investment. Adequate funds should be provided to broadcast stations for training staff and for procuring the necessary equipment. 


\section{Appendix}

Department of Communication Arts

University of Uyo, Uyo

P. M. B. 1017

Uyo

Akwa Ibom State, Nigeria.

Dear Sir/ Madam,

We are conducting a research on Awareness of and Preparedness for Digital Broadcasting among Communication Practitioners and Educators in Uyo.

Kindly complete the attached questionnaire by either ticking the appropriate boxes or writing the answer for each question as appropriate. Rest assured that information given will be treated in strict confidence and for the purpose of this research study only.

Thanks for your co-operation.

Yours Faithfully

Idaresit I. Inwang and Charles Obot, Ph.D 


\section{QUESTIONNAIRE}

\section{COMMUNICATION PRACTITIONERS}

\section{Please tick as appropriate}

1. What is your department in your station of service?

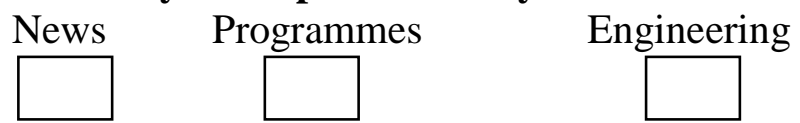

2. What is your educational qualification?
a) WAEC/NECO
b) $\mathrm{OND} / \mathrm{HND}$
c) B.A/M.A
d) $\mathrm{PhD} \&$ above

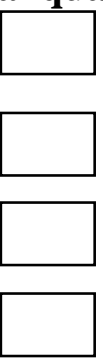

3. What is your year(s) of work in the station?
a) 0-5 years
b) 6-10 years
c) $11-15$ years
d)16-20 years
e) 21-25 years
f) $26-30$
g) $31 \&$ above

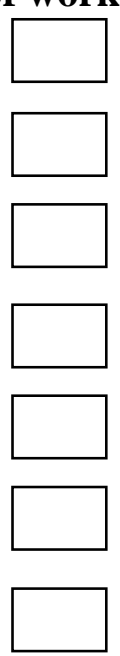

4. Are you familiar with the transition to digitization of broadcast stations in Uyo?
a) Very familiar
b) Somewhat familiar
c) Not familiar at all
d) Do not know

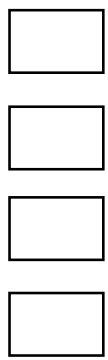


5. Several measures have been used to equip the broadcasters with the necessary knowledge and skills for the transition

a) Strongly agree

b) Agree

c) Strongly disagree

d) Disagree

e) Do not know
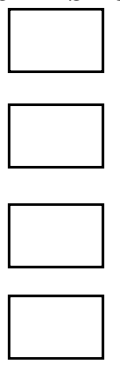

6. In your opinion, what are some of these measures?

a) Workshops

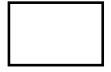

b) Seminars

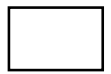

c) Training sessions

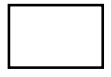

d) Others (specify)

e) None

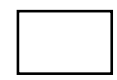

7. How frequent would you say are these measures?
a) Often
b) Sometimes
c) Rarely
d) Never
e) Do not know
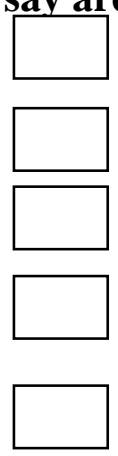

8. Have you personally ever attended any of these?
a) Yes
b) No

9. If "No" to the above, why?

10. In what ways will digitization affect operations in your department? 
11. In your opinion, is your department/organization ready for this transition?

a) Yes

b) No

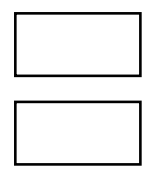

12. In your opinion, what are the possible challenges of digital broadcasting to practitioners?

\section{COMMUNICATION EDUCATORS}

Please tick as appropriate

1. What is your institution of employment

a) University of Uyo

b) Uyo City Polytechnic

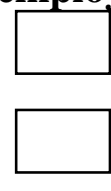

2. Are you aware of transistor to digital broadcasting in Nigeria?

a) Yes

b) No

c) Do not know

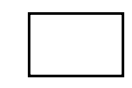

3. In your opinion, who should be responsible for educating students about the digitization of the broadcast industry?

a) Individuals

b) Schools

c) Ministry of Information

d) Practitioners

e) Others (specify)

f) Do not know

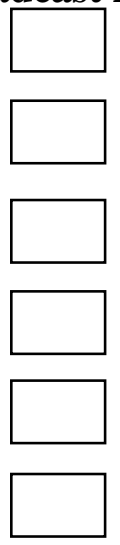


4. In general, how effective would you say digital broadcasting transition awareness campaign has been?

a) Very effective

b) Somewhat effective

c) Not at all effective

d) Do not know

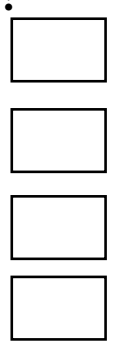

5. Have you ever seen or heard any digital transition message?

a) Yes

b) No

c) Do not know

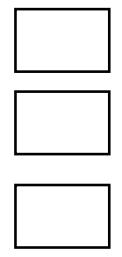

6. If "yes" to the previous question, please state your source.

7. How frequently do you see or hear these messages?
a) Often
b) Sometimes
c) Rarely
d) Never

8. Do you agree that students should be taught about digitization?

a) Strongly agree

b) Agree

c) Strongly disagree

d) Disagree
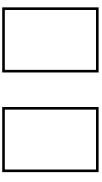

e) Do not know 
9. Is there any course in your department's curriculum that has addressed or will address the recent development?
a) Yes
b) No
c) Cannot say

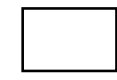

10. If yes to the above (No. 9), can you indicate such course?

11. Have your students already been educated on or made to be aware of this?

a) Yes

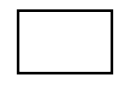

b) No

c) Cannot say

12. If "yes" to No. 11, in what ways?

13. In your opinion, in what ways would the transition to digital broadcasting affect communication education in Nigeria?

(THE QUESTIONNAIRE WAS ADMINISTERED IN PERSON) 


\section{References}

Asemah, E. (2011). Selected Mass Media Themes. Lagos: Spectrum Books Ltd.

Baran, S. J., \& Davis, D. K. (2009). Mass Communication Theory: Foundations, Ferments and Future. Boston, MA: Wadsworth Cengage Learning.

Baran, S. (2010). Introduction to Mass Communication, Media Literacy And Culture (6 ${ }^{\text {th }}$ Edn.). New York: McGraw-Hill.

Graham, A. (2014). Broadcasting Policy in the Digital Age. Retrieved from goo.gl/ i2qbO4. [Accessed: 4 November 2014]

Idoko, O. (2010). The Challenges of Digital Broadcasting in Nigeria. Retrieved from goo.gl/giv1 Vr.

Innocent, P. I. (2012). The Challenges of Digitization of Broadcasting in Nigeria. New Media and Mass Communication, 5, 38-44.

Joseph, C. (2013). Challenges of Digitization in Nigeria (Unpublished Seminar Paper). Department of Communication Arts, University of Uyo, Uyo, Akwa Ibom State, Nigeria.

Kombol, M. (2008). Digital Consideration in Television Production. Makurdi: Switches and Plugs.

Leke, D. (2010). Digital Television Migration in Nigeria: An Assessment. Retrieved from goo.gl/giv1Vr.

Mark, A. (2010). Digital Television Transition in Nigeria: Impact and Challenges. Makurdi Journal of Communication Research, 2(3), 28-35.

McLuhan, M. (1964). Understanding Media: The Extensions of Man. New York: Mentor.

National Council on Information (NCI) (2014). Communiqué Issued at the Extraordinary Meeting on Digitization of Broadcasting and National Security. Abuja.

Ocholi, D. (2009, August 16). A New Dawn in the Broadcast Industry. News Watch.

Ofose, G. (2013, August 17). Is Digital Broadcast Deadline Realistic? Daily Independent.

Okorie, M. (2008). Information and Technology. Enugu: Bezeleel.

Williams, R. (2010). Impact of Digitization of the Broadcasting Media in Nigeria: A Study of Nigerian Television Authority Enugu (Unpublished B.A. thesis). Department of Mass Communication, Caritas University Amorji Nike, Enugu, Nigeria. 